\title{
Hemşirelerin Kanıta Dayalı Hemşirelik Uygulamalarına Yönelik Farkındalık ve Tutumlarının Değerlendirilmesi
}

\section{Evaluation of Awareness and Attitudes of Nurses Towards Evidence-Based Nursing Practices}

\author{
Gonca Karataş Baran ${ }^{1,2 *}$, Sevcan Atasoy ${ }^{2}$, Sevil Şahin ${ }^{3}$ \\ ${ }^{1}$ Sağlık Bilimleri Enstitüsü Hemşirelik Anabilim Dalı Doktora Öğrencisi, Ankara Yıldırım Beyazıt Üniversitesi, \\ ${ }^{2}$ Hemșire, Ankara Keçiören Eğitim ve Araștırma Hastanesi, Ankara \\ ${ }^{3}$ Doç. Dr Öğretim Üyesi, Ankara Yıldırım Beyazıt Üniversitesi, Sağlık Bilimleri Fakültesi \\ e-posta: goncabaran@gmail.com, sevcan-atasoy@ hotmail.com, sevilsahin1@gmail.com \\ Orcid: 0000-0002-7996-6144 \\ Orcid: 0000-0003-3838-1817 \\ Orcid: 0000-0001-7089-6648 \\ *Sorumlu yazar/Corresponding author: Gonca Karataş Baran ${ }^{1}$ \\ Gönderim tarihi/Received:05.03.2020 \\ Kabul tarihi/Accepted:22.05.2020 \\ DOI:10.34087/cbusbed.699410
}

\begin{abstract}
$\mathbf{O z}$
Giriș ve Amaç: Hemşirelerin kanıta dayalı hemşirelik (KDH) uygulamalarına yönelik farkındalıklarını ve hemşirelere verilen $\mathrm{KDH}$ uygulamaları eğitiminin KDH'ye yönelik tutumlarına etkisini değerlendirmektir.

Gereç ve Yöntemler: Çalışma Şubat- Mayıs 2018 tarihleri arasında Ankara'da bir Eğitim Araştırma Hastanesi'nde gerçekleştirilen tanımlayıcı ve yarı deneysel tipte bir araştırmadır. Hastane bünyesinde çalışan, hizmet içi eğitim planında yer alan KDH uygulamaları konulu eğitime katılmış ve araştırmaya katılmayı kabul eden hemşireler $(\mathrm{n}=105)$ örneklemi oluşturmuştur. Veri toplama formu 4 bölümden oluşmaktadır. Birinci bölümde sosyo-demografik özellikler, ikinci bölümde KDH uygulamaları konusunda farkındalık değerlendirme soruları, üçüncü bölümde kanıta dayalı hemşireliğe yönelik tutum ölçeği (eğitim öncesi), dördüncü bölümde bu ölçeğin eğitim sonrası uygulaması yer almaktadır. Verilerin değerlendirilmesinde Wilcoxoen Signed Rank Test, Mann-Whitney U Testi ve Kruskal Wallis Testi kullanılmıştır. İstatistiksel anlamlılık için $\mathrm{p}<0,05$ kabul edilmiştir.

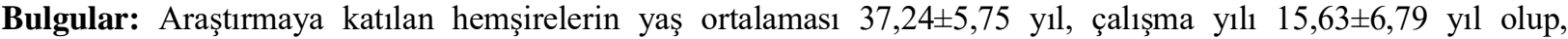
\%34,3'ünün lisans mezunu olduğu, \%59'unun KDH tanımını bilmediği belirlenmiştir. Hemşirelerin eğitim öncesi ve eğitim sonrası KDHYTÖ puanı arasında anlamlı farklılık saptanmıștır $(\mathrm{p}=0,000)$.

Sonuç: $\mathrm{Bu}$ araștırmada; hemșirelerin KDHYTÖ puanının orta düzeyde olduğu ve KDH konulu eğitim sonrası KDHYTÖ toplam puanının arttığı saptanmıştır.

Anahtar kelimeler: Hemşirelik, farkındalık, kanıta dayalı hemşirelik, tutum
\end{abstract}

\footnotetext{
Abstract

Objective: To evaluate the awareness of nurses about evidence-based nursing $(\mathrm{EBN})$ practices and the effects of the training of EBN practices on given to nurses on their attitudes towards EBN.

Materials and Methods: This is a descriptive and semi-experimental study conducted in a Training and Research Hospital in Ankara between February and May 2018. The sample of the nurses $(n=105)$ who participated in the study were included in the training on EBN practices in the in-service training plan of the hospital. The data collection form consists of 4 parts. In the first part, socio-demographic characteristics, in the second part awareness assessment questions about EBN practices, in the third section the attitude towards EBN Questionnaire (pre-training) and in the fourth part the this questionnaire (post-training). Wilcoxoen Signed Rank Test, Mann-Whitney U Test and Kruskal Wallis Test were used to evaluate the data. For statistical significance $\mathrm{p}<0.05$ was accepted.

Results: The mean age of the nurses participating in the study was $37.24 \pm 5.75$ years, the study year was $15.63 \pm 6.79$ years, $34.3 \%$ of them were bachelor's degree, 59\% did not know the definition of EBN. Significant differences were found between nurses' scores of Atitude Towards EBN Questionnaire before and after training $(\mathrm{p}=0.000)$.
} 
Conclusion: In this study, it was found that nurses' scores of atitude EBN Questionnaire were at a moderate level and after the training on EBN, the total score of Attitude Towards EBN Questionnaire was increased.

Key Words: Awareness, attitude, evidence based nursing, nursing

\section{Giriş}

Kanıta dayalı uygulama (KDU); hastalara en iyi bakımı sunabilmek için hasta bakımına ilişkin

birleştirilerek hemşirelik bakımında kullanma yaklaşımı olarak tanımlanmaktadır [1].

KDU, hasta ve ailelerinin çok yönlü gereksinimlerini karşılamada en yüksek bakım kalitesini sağlayan yaklaşımdır. Bir başka ifadeyle kanıta dayalı uygulamalar, var olan en iyi ve güncel kanıtı aramayı, klinik uzmanlıkla değerlendirmeyi yaparken hastanın gereksinim ve tercihlerini göz önünde bulundurmayı kapsayan, klinik karar vermede problem çözme yaklaşımıdır [2].

$\mathrm{KDH}$, deneyimlere dayalı karardan kanıta dayalı karar almaya geçiştir. Son yıllarda dünyada ve ülkemizde sık kullanılan kanıta dayalı sağlık bakımı hemşireliğin araştırmaya dayalı bir meslek olma zorunluluğunu vurgulamaktadır. En iyi kanıt terimi bilimsel veya deneysel kanıt anlamına gelir. Hemşirelikte KDU; kanıta dayalı tıp, kanıta dayalı eğitim ve kanıta dayalı yönetim gibi uygulama alanlarının bir türüdür [3]. Klinik sorunu tanımlamayı, literatür taramayı, araştırma sonuçlarını klinik olarak değerlendirmeyi ve uygun girişimi belirlemeyi içerir [4].

KDU'nın amac1; bilginin yönetimi, maliyeti azaltma ve hasta bakımını en iyi düzeye getirmedir. Araştırma kanıtlarında KDU'nın güvenlik kültürü oluşturduğu, sağlık bakım maliyetini ve hastanede kalma uzunluğunu azalttı̆̆ uygulamaların ortadan kaldırılmasını sağladığı, hasta sonuçlarını iyileştirdiği ve bakım kalitesini yükselttiği gösterilmiştir [5].

KDU hemşirelik alanında, geleneksel uygulamalardan farklı olarak araştırma ve bilgilere dayalı kaliteli hasta bakımının sunulmasını sağlamaktadır [6].

Hemşirelik uygulamalarının kanıta dayalı olması, bakım kalitesini ve bakım sonuçlarını iyileştirmek, klinik uygulamalarda ve hasta bakım sonuçlarında fark yaratmak, bakımı standardize etmek ve hemşire memnuniyetini arttırmak gibi olumlu sonuçlar alınmasını sağlar [7].

KDU; hemşirelerin doğru, önemli, uygulanabilir kanitlar temelinde biyo-psiko-sosyal yönden kaliteli bakım vermek, hemşirelerin kanıta dayalı bilgilerle çalışmasını sağlamak, klinik alanda problemleri çözmek, uygulamalara yenilik getirmek, hemşirelik bakımında farklılıkları azaltmak, etkin karar vermek, uygulama hatalarının en aza indirmek, hemşire memnuniyetini arttırmak, sağlık sisteminde mükemmelliğe ulaşmak açısından önemlidir [1].

Profesyonel bir meslek olarak hemşireliğin gelişebilmesi ancak bilimsel bilginin yorumlanması ve uygulamada kullanılması ile mümkündür. Hemşirelik mesleğinin gelişmesi ve bakım kalitesinin artması için profesyonel hemşirelerin uygulamalarını araştırma sonuçlarına dayalı en iyi kanitlara göre gerçekleştirmeleri önemli bir gerekliliktir. $\mathrm{Bu}$ kararlarda, bilimsel yöntemle elde edilen en iyi kanttların, deneyimler ve hasta tercihleri ile

kanıtların yaşama geçirilebilmesi, hemşirelerin uygulamalarında kanıtları kullanma alışkanlığını kazanmasına, uygulamalarını bilimsel bilgiye dayandırma kültürünün oluşturulmasına ve araştırmaları eleştirel olarak değerlendirme becerilerinin geliştirilmesine bağlıdır.

Hemşirelerin KDH uygulamaları konusunda tutumlarının belirlenmesi, kanıta dayalı hemşirelik uygulamalarının arttırılmasına katkı sağlayacağı düşünülmektedir.

\section{Materyal ve Metot}

\subsection{Araștırma Yöntemi:}

Tanımlayıcı ve yarı deneysel araştırma

2.2.Araştırmanın yapıldiğ yer ve zaman:

Sağlık Bakanlığı'na bağlı Ankara'da bir eğitim araştırma hastanesinde Şubat-Mayıs 2018 tarihlerinde gerçekleştirilmiştir.

\subsection{Arastırmanın Amacl:}

$\mathrm{Bu}$ çalışma ile hemşirelerin, KDH uygulamalarına yönelik farkındalık ve tutumlarını değerlendirmek ve verilen eğitim ile hemşirelerin $\mathrm{KDH}$ uygulamalarına yönelik tutumlarında farklılık oluşturmak amaçlanmıştır.

\subsection{Araștrrmanın Evreni ve Örneklemi:}

Araştırma evrenini Sağlık Bakanlığı'na bağlı Ankara'da bir hastane bünyesinde aktif çalışan hemşireler oluşturmuştur. Çalışmada örneklem hesabına gidilmemiş olup, hastane bünyesinde aktif çalışan ve hastanenin hizmet içi eğitim planında yer alan "KDH Uygulamaları" konulu eğitime katılmış ve araştırmaya katılmayı kabul eden hemşireler örneklemi oluşturmuştur. Araştırmanın tek merkezde yürütülmesi ve veri toplama formlarında yer alan soruların hemşirelerin ifadelerine dayalı olması araştırmanın sınırlılıklarını oluşturmuştur.

\subsection{Araştırmanın Uygulanmast:}

Araştırmanın yapılabilmesi için hastanenin TUEK kurulundan 22.02.2018 tarih ve 15 sayıli ve hastane yönetiminden gerekli izinler alınmıştır. Çalışmanın yapıldığı hastane hizmet içi eğitim programına katılan hemşirelere çalışma hakkında bilgi verilmiş, çalışmanın gönüllülük esasına göre uygulanacağı belirtilmiş ve hemşirelerin bilgilendirilmiş gönüllü oluru alınmıştır. Veri toplama formu 4 bölümden oluşmaktadır. Birinci bölümde sosyo-demografik özellikler, ikinci bölümde kanıta dayalı hemşirelik uygulamaları konusunda farkındalı değerlendirilmiştir. Üçüncü bölümde Kanıta Dayalı Hemşireliğe Yönelik Tutum Ölçeği (KDHYTÖ) bulunmaktadır. Çalışmaya katııımı kabul eden hemşirelerden bu üç bölümün verileri toplanmış, 
sonrasında kanıta dayalı hemşirelik uygulamaları ile ilgili eğitim verilmiştir. Eğitim konuları; kanıta dayalı hemşireliğin tanımı, amacı, neden gerekli olduğu, yararları, aşamaları, kanıt düzeyleri ve hemşirelikte kanıta dayalı uygulama örnekleri yer almaktadır. Eğitim ortalama 60 dakika sürmüş ve Şubat ile Mart ayında olmak üzere iki kez gerçekleştirilmiştir. Eğitimden 4 hafta sonra eğitim öncesi doldurulan 'KDHYTÖ'ün dördüncü bölümde tekrar doldurulması istenmiş ve eğitimin hemşirelerin kanıta dayalı hemşirelik uygulamalarına yönelik tutumlarında farklılık oluşturup oluşturmadığı değerlendirilmiştir.

\subsection{Veri Toplama Araçlar}

Veri toplama formu 4 bölümden oluşmaktadır. Birinci bölümde sosyo-demografik özellikler, ikinci bölümde kanıta dayalı hemşirelik uygulamaları konusunda farkındalık değerlendirme soruları, üçüncü bölümde 'KDHYTÖ' (eğitim öncesi) kullanılmıştır. Dördüncü bölümde 'KDHYTÖ’ (eğitim sonrası) yer almaktadır. KDHYTÖ (Evidence-Based Nursing Attitude Questionnaire-EBNAQ) Ruzafa-Martinez, LopezIbaorra ve Madrigal-Torres (2011) tarafindan İspanya'da çalışan hemşirelerle geliştirilmiştir [8]. Ölçeğin geçerliliği ve güvenirliği ise Ayhan ve arkadaşları tarafından İzmir ilinde üç hastanede (Sağlık Bakanlığı Eğitim Araştırma Hastanesi, Üniversite Hastanesi ve Özel Hastane) çalışan hemşirelerle yapılmıştır Ölçeğin toplam Cronbach $\alpha$ güvenirlik katsayısı 90'dır [9]. Çalışmamızda eğitim öncesi KDHYTÖ güvenilirlik katsayısı 0,888, eğitim sonrası ise 0,889 bulunmuştur. Ölçeğin Türkçe versiyonuna ait izin yazardan mail yoluyla alınmıştır.

\subsection{Araştırma Analizi:}

Çalışmada yer alan bireylerin sayısal değerlerinin normal dağılıma uygunluğu ShapiroWilk testi ile incelenmiştir. Normal dağılım göstermediği belirlenen değişkenlerin tanımlayıcı istatistiklerinin gösteriminde ortanca (min, max) kullanılmıştır. Kategorik değişkenlerde bireylerin dağılımını göstermek amacıyla sayı (n) ve yüzde (\%) verilmiştir. Araştırma grubunun eğitim öncesi ve eğitim sonrası 'KDHYTÖ' puanının farklılığının incelenmesinde Wilcoxen Signed Rank Test uygulanmıştır. Bağımlı gruplarda Wilcoxen Signed Rank Test, bağımsız gruplarda ise MannWhitney U Testi ve Kruskal Wallis Testi kullanılmıştır. İstatistiksel anlamlılık düzeyi $\mathrm{p}<0,05$ olarak kabul edilmiştir.

\section{Bulgular}

Katılımcıların yaş ortalaması $37,24 \pm 5,75$ yıl ( $\mathrm{min}=24$, $\max =53$ ), çalışma yılı ortalaması ise $15,63 \pm 6,79$ 'dur $(\min =3, \max =34)$. Katılımciların sosyo-demografik özelliklerine yönelik veriler Tablo 1'de verilmiştir. Katılımcıların kanıta dayalı hemşirelik uygulamaları konusunda farkındalık değerlendirilmesine yönelik veriler Tablo 2' de verilmiştir.

Tablo 1. Sosyo-demografik özellikler

\begin{tabular}{|c|c|c|}
\hline Özellikler & $\mathrm{n}$ & $\%$ \\
\hline \multicolumn{3}{|l|}{ Eğitim } \\
\hline Sağl1k Meslek Lisesi & 12 & 11,4 \\
\hline Önlisans & 31 & 29,5 \\
\hline Lisans Tamamlama & 19 & 18,1 \\
\hline Lisans & 36 & 34,3 \\
\hline Y lisans ve üzeri & 7 & 6,7 \\
\hline \multicolumn{3}{|l|}{ Çalışılan birim } \\
\hline Servis/Klinik & 47 & 44,8 \\
\hline Yoğun Bakım & 27 & 25,7 \\
\hline Acil & 15 & 14,3 \\
\hline Poliklinik & 6 & 5,7 \\
\hline Diğer (İdare, Kan alma, Endoskopi vb.) & 10 & 9,5 \\
\hline \multicolumn{3}{|l|}{ Yabancı Dil Bilgisi } \\
\hline Yok & 27 & 25,7 \\
\hline $\mathrm{Az}$ & 53 & 50,5 \\
\hline Orta & 25 & 23,8 \\
\hline İyi & 0 & 0 \\
\hline Toplam & 105 & 100 \\
\hline
\end{tabular}


Tablo 2. KDH Uygulamaları Konusunda Farkındalık Değerlendirilmesi

\begin{tabular}{|c|c|c|}
\hline KDH tanımını bilme durumu & $\mathrm{n}$ & $\%$ \\
\hline Evet & 43 & 41,0 \\
\hline Hayır & 62 & 59,0 \\
\hline \multicolumn{3}{|l|}{ Mezun olunan okulda KDH dersi alma durumu } \\
\hline Evet & 12 & 11,4 \\
\hline Hayır & 93 & 88,6 \\
\hline \multicolumn{3}{|l|}{ Calıșlan kurumda KDH eğitimi alma durumu } \\
\hline Evet & 7 & 6,7 \\
\hline Hayır & 98 & 93,3 \\
\hline \multicolumn{3}{|l|}{ Bilgi edinme yolları * } \\
\hline Hemşirelik Eğitimi & 68 & 64,8 \\
\hline Calıșma arkadaşları (usta-çırak ilișkisi) & 90 & 85,7 \\
\hline Deneyimler & 74 & 70,5 \\
\hline Hekimler & 71 & 67,6 \\
\hline Araştırma Sonuçları & 38 & 36,2 \\
\hline Sağlık Bakanlı̆̆ Protokolleri & 32 & 30,5 \\
\hline Diğer & 13 & 12,4 \\
\hline \multicolumn{3}{|l|}{ Literatür tarama durumu } \\
\hline Evet & 21 & 20,0 \\
\hline Hayır & 84 & 80,0 \\
\hline \multicolumn{3}{|l|}{ Veri Tabanı* } \\
\hline İnternet & 16 & 15,2 \\
\hline Google Akademik & 5 & 4,8 \\
\hline Dergiler & 3 & 2,9 \\
\hline PubMed & 5 & 4,8 \\
\hline \multicolumn{3}{|l|}{ Araştırma makalesi okuma durumu } \\
\hline Evet & 39 & 37,1 \\
\hline Hayır & 66 & 62,9 \\
\hline \multicolumn{3}{|l|}{ Elestirel makale eğitimi durumu } \\
\hline Evet & 9 & 8,6 \\
\hline Hayır & 96 & 91,4 \\
\hline \multicolumn{3}{|l|}{ Eleştirel makale değerlendirme durumu } \\
\hline Evet & 3 & 2,9 \\
\hline Hayır & 102 & 97,1 \\
\hline \multicolumn{3}{|l|}{ Bilimsel araştırma yöntemleri eğitimi durumu } \\
\hline Evet & 29 & 27,6 \\
\hline Hayır & 76 & 72,4 \\
\hline \multicolumn{3}{|l|}{ Bilimsel araştırma yapma durumu } \\
\hline Evet & 12 & 11,4 \\
\hline Hayır & 93 & 88,6 \\
\hline \multicolumn{3}{|l|}{ Bilimsel yayın yapma durumu } \\
\hline Evet & 6 & 5,7 \\
\hline Hayır & 99 & 94,3 \\
\hline \multicolumn{3}{|l|}{ Bilimsel yayın türü* } \\
\hline Makale & 5 & 4,8 \\
\hline Sözel bildiri & 1 & 1,0 \\
\hline Poster sunumu & 1 & 1,0 \\
\hline Tez & 2 & 2,0 \\
\hline \multicolumn{3}{|l|}{ Bilimsel toplantılara katılım durumu } \\
\hline Evet & 26 & 24,8 \\
\hline Hayır & 79 & 75,2 \\
\hline \multicolumn{3}{|l|}{ KDH uygulamalarında engeller ile ilgili görüşler * } \\
\hline Eleman azlığı & 63 & 60,0 \\
\hline Ortam ve malzeme yetersizliği & 35 & 33,3 \\
\hline Zaman azlığı & 61 & 58,1 \\
\hline İș yoğunluğu & 92 & 87,6 \\
\hline İs merkezli çalışma & 67 & 63,8 \\
\hline Bilgi eksikliği & 63 & 60,0 \\
\hline Kurumsal destek yetersizliği & 51 & 48,6 \\
\hline Araștırmalara ulaşamama & 21 & 20,0 \\
\hline Bilimsel araştırma yöntemleri konusunda bilgi eksikliği & 53 & 50,5 \\
\hline Yabancı dil yetersizliği & 64 & 61,0 \\
\hline Klinikte karar verici olamama & 46 & 43,8 \\
\hline Diğer & 2 & 1,9 \\
\hline Toplam & 105 & 100 \\
\hline
\end{tabular}


Katılımcıların KDHYTÖ puanının; eğitim öncesi ort. \pm ss: $58,18 \pm 7,91$, ortanca (min, $\max )=58,00(38-75)$ iken, eğitim sonrası ort. \pm ss: $61,81 \pm 6,68$, ortanca $(\min , \max )=61,00(45-75)$ olduğu saptanmıştır.
Katılımcıların KDHYTÖ toplam puanının ve alt boyutlar puanının KDH Uygulamaları eğitimi öncesisonrası karşılaştırması Tablo 3’te verilmiştir.

Tablo 3. Eğitim Öncesi- Sonrası KDHYTÖ Puanı

\begin{tabular}{|c|c|c|c|c|}
\hline \multirow{2}{*}{$\frac{\text { KDHYTÖ Toplam Puanı Tanımlayıcı Verileri }}{\text { Ortalama } \pm \text { SS /Ortanca (Min-Max) }}$} & \multicolumn{2}{|c|}{ Ĕgitim Öncesi } & \multicolumn{2}{|c|}{ Eğitim Sonrası } \\
\hline & $58,18 \pm 7,91$ & $58,00(38-75)$ & $61,81 \pm 6,68$ & $61,00(45-75)$ \\
\hline \multicolumn{5}{|l|}{ Alt Boyutlar } \\
\hline $\begin{array}{l}\text { Kanıta Dayalı Hemşireliğe Yönelik İnanç ve } \\
\text { Beklentiler }\end{array}$ & $27,02 \pm 4,43$ & $28,00(7-35)$ & $29,20 \pm 3,18$ & $28,00(21-35)$ \\
\hline Kanita Dayalı Uygulama Niyeti & $14,74 \pm 2,81$ & $15,00(9-20)$ & $15,63 \pm 2,51$ & $16,00(9-20)$ \\
\hline Kanıta Dayalı Hemşirelikle İlgili Duygular & $16,34 \pm 2,34$ & $16,00(7-20)$ & $17,00 \pm 2,15$ & $17,00(8-20)$ \\
\hline $\begin{array}{l}\text { Eğitim Sonrası- Eğitim Öncesi KDHYTÖ Toplam } \\
\text { Puan }\end{array}$ & $\underset{(105)}{\mathbf{n}}$ & Sira Ortalaması & Sıra Toplamı & $\begin{array}{c}\text { İstatistiksel } \\
\text { Analiz }\end{array}$ \\
\hline & $\begin{array}{l}11^{a} \\
78^{b} \\
16^{c}\end{array}$ & $\begin{array}{l}37,36 \\
46,08\end{array}$ & $\begin{array}{r}411,00 \\
3594,00\end{array}$ & $\begin{array}{r}Z=-6,522 \\
\mathbf{P}=\mathbf{0 , 0 0 0}\end{array}$ \\
\hline \multicolumn{5}{|l|}{$\begin{array}{l}\text { Eğitim Sonras1- Eğitim Öncesi KDHYTÖ İnanç ve } \\
\text { Beklentiler Boyutu }\end{array}$} \\
\hline & $\begin{array}{l}12^{a} \\
68^{b} \\
25^{c}\end{array}$ & $\begin{array}{l}21,71 \\
43,82\end{array}$ & $\begin{array}{r}260,50 \\
2979,50\end{array}$ & $\begin{array}{r}Z=-6,550 \\
\mathbf{P}=\mathbf{0 , 0 0 0}\end{array}$ \\
\hline \multicolumn{5}{|l|}{$\begin{array}{l}\text { Eğitim Sonras1- Eğitim Öncesi KDHYTÖ Niyet } \\
\text { Boyutu }\end{array}$} \\
\hline & $\begin{array}{l}12^{a} \\
59^{b} \\
34^{c}\end{array}$ & $\begin{array}{l}37,50 \\
35,69\end{array}$ & $\begin{array}{r}450,00 \\
2106,00\end{array}$ & $\begin{array}{r}Z=-4,816 \\
\mathbf{P}=\mathbf{0 , 0 0 0}\end{array}$ \\
\hline \multicolumn{5}{|l|}{$\begin{array}{l}\text { Eğitim Sonras1- Eğitim Öncesi KDHYTÖ Duygular } \\
\text { Boyutu }\end{array}$} \\
\hline & $\begin{array}{l}16^{a} \\
49^{b} \\
40^{c}\end{array}$ & $\begin{array}{l}35,75 \\
32,10\end{array}$ & $\begin{array}{r}572,00 \\
1573,00\end{array}$ & $\begin{array}{r}Z=-3,307 \\
\mathbf{P}=\mathbf{0 , 0 0 1}\end{array}$ \\
\hline
\end{tabular}

Wilcoxoen Signed Rank Test, $a=$ Eğitim Sonrası toplam $<$ Eğitim Öncesi toplam, $b=$ Ĕgitim Sonrası toplam $>$ Ĕgitim Öncesi toplam,c= Ĕ̈itim Sonrası toplam $=$ Ĕgitim Öncesi toplam

KDHYTÖ toplam puanının ve alt boyutlar (İnanç ve Beklentiler Boyutu, Niyet Boyutu, Duygular Boyutu) puanlarının eğitim sonrasında eğitim öncesine göre anlamlı derecede fazla olduğu tespit edilmiş̧tir. Analizin tanımlayıcı verileri tablonun üstüne yerleştirilmiştir. Katılımcıların eğitim öncesi-sonrası KDHYTÖ puanı ortalamasının sosyo-demografik ve KDH uygulamaları konusunda farkındalık özelliklerine ait değişkenlere göre karşılaştırması Tablo 4'te verilmiştir.

\section{Tartışma}

Çalışmamızda hemşirelerin KDH tanımını bilme, mezun olunan okulda ve çalıştığ kurumda KDH uygulamalarına yönelik eğitim alma, literatür tarama, araştırma makalesi okuma, eleştirel makale değerlendirme eğitimi alma, eleştirel makale değerlendirme, bilimsel araştırma yöntemleri eğitimi alma, bilimsel araştırma yapma, bilimsel yayın yapma, bilimsel toplantılara katılma durumunun düşük olduğu saptanmıştır. Ülkemizde yapılan çalışmalarda, çalışmamızla benzer olarak hemşirelerin bilimsel araştırma yapma, bilimsel etkinliklere katılma ve bilimsel mesleki bir dergi takip etme oranlarının oldukça düşük olduğu saptanmıştır [10-
12]. Melnyk ve arkadaşları; araştırma yöntemleri hakkında bilgi edinmenin, araştırma raporlarını eleştirel olarak değerlendirme becerisine sahip olmanın araştırma bulgularının uygulanmasını engelleyen engellerin aşılmasını sağlayabildiğini ve böylece sağlık hizmet kalitesinin iyileştirilmesine yol açabileceğini belirtmiştir. $\mathrm{Bu}$ nedenle, KDU tutumu, bilgisi ve hemşirelerin becerileri çok önemlidir [13].

Ülkemizde Dikmen ve ark.'nın yaptığı bir çalışmada

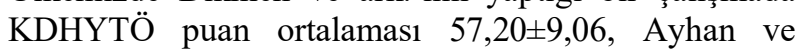

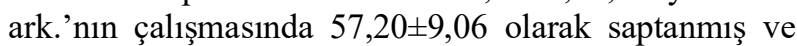
puanın orta düzeyde olduğu belirtilmiştir $[9,14]$. Bizim çalışmamızda da eğitim öncesi KDHYTÖ puanı ortalamas $58,18 \pm 7,91$, ortanca $(\min , \max )=58,00(38$ 75) iken, eğitim sonrası KDHYTÖ puan ortalaması $61,81 \pm 6,68$, ortanca $(\min , \max )=61,00(45-75)$ olduğu saptanmıştır. Yılmaz ve ark.'nın çalışmasında KDHYTÖ puan ortalaması 46,36 $\pm 3,95$ 'dir, Kanita Dayalı Hemşireliğe Yönelik İnanç ve Beklentiler alt boyut puan ortalaması 28,30 $\pm 3,90$, Kanita Dayalı Uygulama Niyeti alt boyut puan ortalamasi $10,55 \pm 1,93$, Kanita Dayalı Hemşirelikle İlgili Duygular alt boyut puan ortalaması 
Tablo 4. Eğitim Öncesi-Sonrası KDHYTÖ Puanının Bazı Değişkenlere Göre Karşılaştırılması

\begin{tabular}{|c|c|c|c|c|c|}
\hline Sosyo Demografik Özellikler & nn & $\begin{array}{l}\text { KDHYTÖ puanı } \\
\text { (eğitim öncesi) } \\
\text { Sıra Ortalaması }\end{array}$ & $\begin{array}{l}\text { Ístatistiksel } \\
\text { Analiz }\end{array}$ & $\begin{array}{l}\text { KDHYTÖ puanı } \\
\text { (eğitim sonrası) } \\
\text { Sıra Ortalaması }\end{array}$ & $\begin{array}{l}\text { İstatistiksel } \\
\text { Analiz }\end{array}$ \\
\hline \multicolumn{6}{|l|}{ Eğitim } \\
\hline Sağllk Meslek Lisesi & 12 & $28,08^{\text {a }}$ & $\mathrm{X}^{2}=25,745$ & $31,08^{\mathrm{a}}$ & $\mathrm{X}^{2}=17,126$ \\
\hline Önlisans & 31 & 53,48 & $\mathrm{df}=4$ & 52,40 & $\mathrm{df}=4$ \\
\hline Lisans Tamamlama & 19 & $34,21^{b}$ & $P=0,000$ & 40,32 & $P=0,002$ \\
\hline Lisans & 36 & $67,31^{\mathrm{a}, \mathrm{b}}$ & & $63,44^{a}$ & \\
\hline Y lisans ve üzeri & 7 & 71,00 & & 73,93 & \\
\hline \multicolumn{6}{|l|}{ Yaș } \\
\hline $21-30$ & 18 & 66,33 & $\mathrm{X}^{2}=7,929$ & 64,58 & $\mathrm{X}^{2}=5,723$ \\
\hline $31-40$ & 57 & 53,82 & $\mathrm{df}=3$ & 53,05 & $\mathrm{df}=3$ \\
\hline $41-50$ & 29 & 42,19 & $P=0,048$ & 44,69 & $\mathrm{P}=0,126$ \\
\hline $51-60$ & 1 & 79,50 & & 82,50 & \\
\hline \multicolumn{6}{|l|}{ Çalıșma yılı } \\
\hline $0-10$ & 25 & 63,70 & $X^{2}=7,561$ & 61,02 & $\mathrm{X}^{2}=4,873$ \\
\hline $11-20$ & 51 & 53,30 & $\mathrm{df}=3$ & 53,16 & $\mathrm{df}=3$ \\
\hline $21-30$ & 28 & 41,95 & $\mathrm{P}=0,056$ & 44,50 & $\mathrm{P}=0,181$ \\
\hline $31-40$ & 1 & 79,50 & & 82,50 & \\
\hline \multicolumn{6}{|l|}{ Çalıșılan Birim } \\
\hline Servis/Klinik & 47 & $49,16^{\mathrm{a}}$ & $X^{2}=15,987$ & 47,72 & $\mathrm{X}^{2}=11,576$ \\
\hline Yoğun Bakım & 27 & $58,61^{\mathrm{b}}$ & $\mathrm{df}=4$ & 60,00 & $\mathrm{df}=4$ \\
\hline Acil & 15 & 52,60 & $P=0,003$ & 55,03 & $P=0,021$ \\
\hline Poliklinik & 6 & $18,17^{a, b, c}$ & & $26,00^{\mathrm{a}}$ & \\
\hline Diğer & 10 & $77,40^{\mathrm{c}}$ & & $72,05^{\mathrm{a}}$ & \\
\hline \multicolumn{6}{|l|}{ Yabancı Dil Bilgisi } \\
\hline Yok & 27 & 37,24 a, & $X^{2}=16,958$ & $38,19^{\text {a }}$ & $\mathrm{X}^{2}=13,910$ \\
\hline $\mathrm{Az}$ & 53 & $52,11^{b}$ & $\mathrm{df}=2$ & $52,70^{b}$ & $\mathrm{df}=2$ \\
\hline Orta & 25 & $71,90^{\mathrm{a}, \mathrm{b}}$ & $P=0,000$ & 69,64 a,b & $\mathbf{P}=\mathbf{0 , 0 0 1}$ \\
\hline İyi & 0 & - & & - & \\
\hline $\begin{array}{lr}\text { KDH } & \text { Uygulamaları } \\
\text { Konusunda } & \text { Farkındalık } \\
\text { Özellikleri } & \\
\end{array}$ & nn & $\begin{array}{l}\text { KDHYTÖ puanı } \\
\text { (eğitim öncesi) } \\
\text { Ortanca(min-max) } \\
\end{array}$ & $\begin{array}{l}\text { İstatistiksel } \\
\text { Analiz }\end{array}$ & $\begin{array}{l}\text { KDHYTÖ puanı } \\
\text { (eğitim sonrası) } \\
\text { Ortanca(min-max) }\end{array}$ & $\begin{array}{l}\text { İstatistiksel } \\
\text { Analiz }\end{array}$ \\
\hline \multicolumn{6}{|l|}{ KDH Tanımını Bilme Durumu } \\
\hline Evet & 43 & $63,00(43-75)$ & $Z=-5,153$ & $65,00(45-75)$ & $\mathrm{Z}=-3,441$ \\
\hline Hayır & 62 & $56,00(38-67)$ & $\mathbf{P}=\mathbf{0 , 0 0 0}$ & $60,00(46-75)$ & $\mathrm{P}=0,001$ \\
\hline \multicolumn{6}{|l|}{ KDH Dersi Alma Durumu } \\
\hline Evet & 12 & $65,50(43-75)$ & $Z=-2,411$ & $65,50(45-75)$ & $Z=-2,195$ \\
\hline Hayır & 93 & $58,00(38-75)$ & $P=0,016$ & $60,00(46-75)$ & $P=0,028$ \\
\hline \multicolumn{6}{|l|}{ KDH Eğitimi Alma Durumu } \\
\hline Evet & 7 & $61,00(43-75)$ & $Z=-1,164$ & $63,00(45-75)$ & $\mathrm{Z}=-0,322$ \\
\hline Hayır & 98 & $58,00(38-75)$ & $\mathrm{P}=0,244$ & $61,00(46-75)$ & $\mathrm{P}=0,748$ \\
\hline \multicolumn{6}{|l|}{ Literatür Tarama Durumu } \\
\hline Evet & 21 & $65,00(43-75)$ & $Z=-4,409$ & $68,00(54-75)$ & $\mathrm{Z}=-4,458$ \\
\hline Hayır & 84 & $57,50(38-75)$ & $\mathbf{P}=\mathbf{0 , 0 0 0}$ & $60,00(45-75)$ & $P=0,000$ \\
\hline \multicolumn{6}{|l|}{ Makale Okuma Durumu } \\
\hline Evet & 39 & $61,00(47-75)$ & $Z=-2,840$ & $61,00(51-75)$ & $\mathrm{Z}=-1,674$ \\
\hline Hayır & 66 & $58,00(38-75)$ & $P=0,005$ & $61,00(45-74)$ & $\mathrm{P}=0,094$ \\
\hline \multicolumn{6}{|l|}{ Eleştirel Makale Eğitimi Durumu } \\
\hline Evet & 9 & $68,00(43-75)$ & $\mathrm{Z}=-3,313$ & $73,00(45-75)$ & $\mathrm{Z}=-3,452$ \\
\hline Hayır & 96 & $88,00(38-75)$ & $\mathbf{P}=\mathbf{0 , 0 0 1}$ & $60,00(46-75)$ & $P=0,001$ \\
\hline \multicolumn{6}{|c|}{ Eleștirel Makale Değerlendirme Durumu } \\
\hline Evet & 3 & $58,00(43-75)$ & $\mathrm{Z}=-0,058$ & $62,00(45-75)$ & $\mathrm{Z}=-0,173$ \\
\hline Hayır & 102 & $58,00(38-75$ & $\mathrm{P}=0,954$ & $61,00(46-75)$ & $\mathrm{P}=0,862$ \\
\hline \multicolumn{6}{|c|}{ Bilimsel araştırma Yöntemleri Eğitimi Alma Durumu } \\
\hline Evet & 29 & $63,00(43-75)$ & $\mathrm{Z}=-2,516$ & $65,00(45-75)$ & $\mathrm{Z}=-2,273$ \\
\hline Hayır & 76 & $58,00(38-75)$ & $\mathbf{P}=\mathbf{0 , 0 1 2}$ & $60,00(46-74)$ & $P=0,023$ \\
\hline \multicolumn{6}{|c|}{ Bilimsel Araștırma Yapma Durumu } \\
\hline Evet & 12 & $64,00(43-75)$ & $\mathrm{Z}=-2,134$ & $64,50(45-75)$ & $\mathrm{Z}=-2,533$ \\
\hline Hayır & 93 & $58,00(38-75)$ & $\mathbf{P}=\mathbf{0 , 0 3 3}$ & $60,00(46-75)$ & $P=0,011$ \\
\hline \multicolumn{6}{|l|}{ Bilimsel Yayın Yapma Durumu } \\
\hline Evet & 6 & $61,00(43-75)$ & $Z=-0,906$ & $64,00(54-75)$ & $\mathrm{Z}=-1,369$ \\
\hline Hayır & 99 & $58,00(38-75)$ & $\mathrm{P}=0,365$ & $61,00) 45-75)$ & $\mathrm{P}=0,171$ \\
\hline Bilimsel Toplantılara Katılım & & & & & \\
\hline Evet & 26 & $60,50(38-75)$ & $Z=-2,305$ & $64,00(45-75)$ & $\mathrm{Z}=-2,733$ \\
\hline Hayır & 79 & $58,00(43-75)$ & $\mathrm{P}=\mathbf{0 , 0 2 1}$ & $60,00) 46-75)$ & $P=0,006$ \\
\hline
\end{tabular}

$X^{2}=$ Kruskal Wallis test

$Z=$ Mann Whitney $U$ test 
ise 7,51 $\pm 2,45$ olarak saptanmıştır [15]. Çalışmamızda ise; eğitim öncesi ve sonrası sırası ile Kanıta Dayalı Hemşireliğe Yönelik İnanç ve Beklentiler alt boyut puan ortalamas1 27,02 $\pm 4,43,29,20 \pm 3,18$; Kanita Dayalı Uygulama Niyeti alt boyut puan ortalamasi $14,74 \pm 2,81$, 15,63 $\pm 2,51$, Kanıta Dayalı Hemşirelikle İlgili Duygular alt boyut puan ortalamasi ise 16,34 $\pm 2,34,17,00 \pm 2,15$ olarak saptanmıştır. Yukarıdaki çalışma sonuçlarıyla karşılaştırıldığında; çalışmamıza katılan hemşirelerin KDHYTÖ toplam puanlarının, bu çalışma sonuçlarına göre daha yüksek olduğu görülmektedir. Eğitim

sonrasında ise bu puanlar artmıştır ve eğitim sonrasında eğitim öncesine göre anlamlı farklılık olduğu tespit edilmiştir. Bazı araştırma bulguları, KDU'ya yönelik tutum değiştirmenin ve hemşirelerin bilgisinin arttırılmasının KDU'da ilk adım olduğunu göstermiştir [16]. McCleary ve Brown'un çalışmasında, hemşirelerin KDU bilgisinin ve buna yönelik olumlu tutumlarının sağlık sistemindeki uygulamasına katkıda bulunacağını bildirmiştir [17].

Koehn ve Lehman'ın çalışmasında hemşirelerin eğitim düzeyinin kanıta dayalı hemşireliğe yönelik tutumlarını etkilediği ve etkinin yüksek lisans derecesine sahip hemşirelerden kaynaklandığını belirtmişlerdir [18]. Çalışmamızda ise; eğitimin KDHYTÖ puanını etkilediği ve bu etkinin lisans hemşirelik derecesine sahip hemşirelerden kaynaklandığı tespit edilmiştir. Yüksek lisans ve üzeri eğitim düzeyine sahip hemşirelerde ölçek puanı daha yüksek iken, bu hemşirelerin sayısının az olması nedeniyle anlamlı farklılık tespit edilemediği düşünülmektedir. Buna karşın, Ruzafa-Martinez ve arkadaşları, Dikmen ve arkadaşları ile Ayhan ve arkadaşlarının çalışmalarında ise; hemşirelerin eğitim düzeylerinin, KDHYTÖ toplam puanını etkilemediği bulunmuştur $[8,9,14]$.

Çalışmalarda hemşirelerin yaş ve meslekte çalıştıkları sürelerinin, kanıta dayalı hemşireliğe yönelik tutumlarını etkilemediği görülmüştür $[8,9,14]$. Çalışmamızda ise yaş faktöründe eğitim öncesi istatistiksel anlamlılık düzeyine yakın bir anlamlılık mevcutken, eğitim sonrası anlamlılık saptanmamıştır. Çalışmamızda hemşirelerin meslekte çalışma süresinin, KDH'e yönelik tutumlarında eğitim öncesi-sonrası literatür ile uyumlu olarak anlamlı farklılık bulunmadığı görülmüştür. Çalışmamızda çalışılan birim ve yabancı dil bilgisi KDHYTÖ toplam puanını etkilemektedir. Eğitim öncesi serviste, yoğun bakımda ve diğer birimlerde çalışanlar poliklinikte çalışanlara göre daha yüksek ölçek puanına sahipken, eğitim sonrası diğer birimlerde çalışanlar poliklinikte çalışanlara göre daha yüksek ölçek puanına sahiptir. Yabancı dil bilgisi orta düzeyde olanların hem eğitim öncesi hem sonrası, dil bilgisi az ve olmayanlara göre KDHYTÖ toplam puanı anlamlı derecede daha yüksektir.

Hemşirelerin KDH'ın tanımını biliyor olmasının, eğitiminde $\mathrm{KDH}$ ile ilgili ders almış olmasının, literatür tarıyor olmasının, eleştirel makale değerlendirme eğitimi almış olmasının, bilimsel araştırma yöntemleri konusunda eğitim almış olmasının, bilimsel araştırma yapmış olmasının ve bilimsel toplantılara katılıyor olmasının KDH'e yönelik tutumlarını olumlu yönde etkilediği ve bu özellikleri taşıyan hemşirelerin KDHYTÖ toplam puanının yüksek olduğu saptanmıştır $(p<0,05)$. Taş Aslan ve Çelen'in hemşirelik öğrencileriyle yaptığı çalışmasında; çalışmasında hemşirelik mesleği ile ilgili dergi okuyan, bilimsel toplantılara katılan, mezun olduktan sonra meslekle ilgili bilimsel araştırma yapmaya istekli olan öğrencilerin kanıta dayalı hemşireliğe yönelik tutum puanları yüksek bulunmuştur [19]. Yılmaz ve ark.'nın çalışmasında hemşirelerin mesleki yayınları düzenli takip etme durumları ile KDHYTÖ toplam puan ortalamaları arasında anlamlı bir fark bulunmuştur [15]. Dikmen ve arkadaşlarının çalışmasında da bilimsel araştırma sonuçlarını ve mesleki dergileri düzenli takip eden hemşirelerin, diğer hemşirelere göre kanita dayalı hemşireliğe yönelik tutumlarının anlamlı düzeyde yüksek olduğu saptanmıştır [14]. McCleary ve Brown (2003) tarafindan yapılan çalışmada hemşirelik eğitimi sırasında verilen araştırma dersleri ile elde edilen araştırma bilgisinin, araştırma sonuçlarını kullanma konusundaki tutumu olumlu yönde etkilediği saptanmıştır [20]. Özdemir ve Akdemir tarafından yapılan çalışmada da araştırma konusunda bilgi sahibi olduğunu belirten hemşirelerin araştırma sonuçlarını uygulamada daha fazla kullandıkları belirtilmiştir [21]. Dikmen ve arkadaşları ile Ayhan ve arkadaşlarının yaptıkları çalışmalarda; bilimsel toplantılara katılan hemşirelerin KDHYTÖ puan ortalaması, bilimsel toplantılara katılmayan hemşirelerin puan ortalamasından anlamlı olarak yüksek bulunmuştur $[9,14]$. Çalışma sonucumuz bu araştırma sonuçları ile benzerlik göstermektedir. Araştırma bilgi ve becerisi olan hemşirelerin öğrendikleri bilgiyi klinik ortamda değerlendirebildiği, bilimsel araştırma yapanların ve bilimsel toplantılara katılan hemşirelerin güncel bilgilerden haberdar olduğu ve bu durumların KDU yönelik tutumlarını olumlu yönde etkilediği düşünülmektedir.

Çalışmamızda hemşireler; iş yoğunluğu, iş merkezli çalışma, eleman azlığı, zaman azlığı, bilgi eksikliği, yabancı dil yetersizliği, bilgi eksikliği, araştırmalara ulaşamama, kurumsal destek yetersizliği gibi KDU'ya yönelik bir dizi engellerin olduğunu ifade etmişlerdir. Çalışmamızdan ve diğer çalışmalardan elde edilen bulgulardan, sağlık profesyonellerinin KDU'larını mesleğine entegre etme önünde engellerin benzer olduğu görülmektedir [22-24]. Kanıtları klinik uygulamalara entegre etmek sağlık çalışanlarında davranış değişikliğinin yanı sıra sağlık hizmetleri sisteminde değişiklikleri de içeren karmaşık bir süreçtir [25]. Ancak, KDU inançları, KDU, örgüt kültürü, grup uyumu ve klinisyenlerdeki iş doyumu arasındaki ampirik ilişkiler henüz belirlenmemiştir. Bu ilişkilerin anlaşılması, sağlık profesyonellerinde, bakım kalitesini, hasta çıktılarını ve iş memnuniyetini arttırma amacıyla kanıtların uygulamaya dönüştürülmesini artıran müdahalelere rehberlik etmede anahtar olabilir. Bulgular, sağlık sistemlerinde KDU'yu kolaylaştıran kültürler oluşturmak ve hemşirelerin/sağlık çalışanlarının 
KDU'nun değeri hakkındaki bilişsel inançlarını güçlendirmek, bakım ve hasta sonuçlarını iyileştirmek ve iş memnuniyetini arttırmak için uygulama yeteneklerini güçlendirme ihtiyacını desteklemektedir [25].

\section{Sonuç ve Öneriler}

Çalışmamı sonucunda hemşirelerinin $\mathrm{KDH}$ uygulamaları konusunda farkındalıklarının (KDH tanımını bilme, mezun olunan okulda ve çalıştığ kurumda $\mathrm{KDH}$ uygulamalarına yönelik eğitim alma, literatür tarama, araştırma makalesi okuma, eleştirel makale değerlendirme, bilimsel araştırma yapma, bilimsel yayın yapma, bilimsel toplantılara katılma...gibi) düşük olduğu belirlenmiştir. KDHYTÖ ölçeği puanının eğitim sonrası eğitim öncesine göre yüksek olduğu ve bu eğitimin hemşirelerin $\mathrm{KDH}$ uygulamaları konusunda farkındalıklarını arttırmada yararlı olduğu görülmüştür.

Hemşirelerin $\mathrm{KDH}$ uygulamaları konusunda farkındalıklarını arttıracak hizmet içi eğitim programlarının düzenlenmesinin yararlı olacağı düşünülmektedir.

Her hastanede KDU konusunda gelişmeleri takip edecek ve ilgili birimler ile paylaşacak bir birim oluşturulması önerilir. $\mathrm{Bu}$ şekilde eleman eksikliği, iş yoğunluğu nedeniyle KDU konusunda engellerin ortadan kaldırabileceği, hemşirelerin KDU'lardan daha kolay haberdar olabileceği düşünülmektedir. Bu sayede KDU klinik uygulamalara entegre edilmesi kolaylaşacak, KDU kurum kültürü gelişecektir.

$\mathrm{Bu}$ sonuçlar doğrultusunda, hemşirelerinin bilimsel toplantılara (kongre, sempozyum ve kurslar) katılımlarının desteklenmesi, bu amaçla gerekli izin ve maddi desteğin sağlanması, bilimsel faaliyetlerde aktif rol almaları ve mesleki yayınları/araştırma sonuçlarını takip edebilmeleri konusunda teşvik edilmesi önerilebilir.

\section{Teşekkürler}

Çalışmaya katılan değerli hemşirelere teşekkürlerimizi sunarı.

\section{Referanslar}

1. Kocaman, G, Hemşirelikte kanıta dayalı uygulamalar, Hemşirelikte Araştırma Geliştirme Dergisi, 2003,2,61-69.

2. Babadağ K, Kara M, Kanıta dayalı hemşirelik ve meslekleşme, Atatürk Üniversitesi Hemşirelik Yüksekokulu Dergisi, 2004,7(2),112117.

3. French, P, The development of evidence-based nursing, Journal of Advanced Nursing, 1999, 30(1), 72-78.

4. White, S, Evidence-based practice and nursing, The new panacea? British Journal of Nuring, 1997,6(3), 175-178.

5. Beyea, SC, Slattery, MJ, Evidence-based practice in nursing: A Guide to Successful Implementation, 1 st ed., Marblehead, Healthcare Compliance Company, 2006.

6. Borbasi, S, Jackson, D, Lockwood, C, Undertaking a clinical audit, Courtney, M.D. (Ed.), Evidence for nursing practice,1 st ed, Sydney, Australia, Elsevier Company, 2005, pp.148-167.

7. Yurtsever, S, Altık, M. Kanıta dayalı uygulamalar ve hemşirelik, Fırat Üniversitesi Sağllk Bilimleri Dergisi, 2006, 20(2),159-166.

8. Ruzafa-Martinez, M, Lopez-Iborra, L, Madrigal- Torres, M. Attitude towards evidence-based nursing questionnaire: development and psychometric testing in Spanish community nurses, Journal of Evaluation in Clinical Practice, 2011, 17,664-670.

9. Ayhan, Y, Kocaman, G, Bektaş, M, Kanıta Dayalı Hemşireliğe Yönelik Tutum Ölçeğinin Türkçe'ye Uyarlanması: Geçerlik ve Güvenirlik Çalışması, Hemşirelikte Araştırma Geliştirme Dergisi, 2015,17(2-3), 21-35, http://hemarge.org.tr/dergi/sayi/39.

10. Yava, A, Tosun, N, Çiçek, H, Yavan, T, Terakye, G, Hatipoğlu, S, Hemşirelerin Araştırma Sonuçlarını Kullanımında Engeller Ölçeği'nin geçerlilik ve güvenirliği, Gülhane Tıp Dergisi, 2007, 49, 72-80.

11. Bahar, Z, Gözüm, S, Beşer, A, Çapık, C, Kıssal, A, Gördes Aydoğdu, N, Ersin, F, İki farklı bölgedeki üniversite hastanelerinde çalışan hemşirelerin araştırma kullanım engelleri ve etkileyen etmenlerin incelenmesi, Dokuz Eylül Üniversitesi Hemşirelik Fakültesi Elektronik Dergisi, 2015, 8(4), 232-340.

12. Karadaş, A, Duran, S, Ergün, S, Hemşirelik öğrencilerinin hemşirelikte araştırma, gelişmelere karşı farkındalık ve tutumları, Uluslararası Hakemli Hemşirelik Araştırmaları Dergisi, 2015, 5, 118.

13. Melnyk, BM, Fineout-Overholt, E, Stone, P, Ackerman, M, Evidence-based practice: The past, the present, and recommendations for the millennium, Pediatric Nursing, 2000, 26(1), 77-80.

14. Dikmen, Y, Filiz, NY, Tanrikulu, F, Yilmaz, D, Kuzgun, H, Attitudes of intensive care nurses towards evidence-based nursing, International Journal of Health Sciences and Research, 2018, 8, 138143.

15. Yılmaz, D, Düzgün, F, Dikmen, Y, Hemşirelerin kanıta dayalı hemşireliğe yönelik tutumlarının incelenmesi, Acıbadem Üniversitesi Sağllk Bilimleri Dergisi, 2018, 10(4), 713-719. https://doi.org/10.31067/0.2018.91

16. Krugman, M, Evidence-based practice, the role of staff development, Journal for Nurses in Staff Development, 2003, 19(6), 279-287, doi: 10.1097/00124645-200311000-00003.

17. McCleary, L, Brown, GT, Research utilization among pediatric health professionals, Nursing and Health Science, 2002, 4(4), 163171, doi: 10.1046/j.1442-2018.2002.00124.x

18. Koehn, ML, Lehman, K, Nurses' perceptions of evidence-based nursing practice, Journal of Advanced Nursing, 2008, 62, 209-215.

19. Taş Arslan, F, Çelen, R, Hemşirelik öğrencilerinin kanıta dayalı hemşireliğe yönelik tutumlarının belirlenmesi, Sürekli Tip Ĕ̈itimi Dergisi, 2018, 27(2), 99-106.

20. McCleary, L, Brown, GT, Association between nurses' education about research and their research use, Nurse Education Today, 2003, $23,556-565$.

21. Özdemir, L, Akdemir, N, Turkish nurses' utilization of research evidence in clinical practice and influencing factors, International Nursing Review, 2009, 56, 319-325.

22. Platin, N, Kanıta dayalı hemşirelik ülkemizde uygulanamaz: Neden? I. Uluslararası\&VIII. Ulusal Hemşirelik Kongresi, 29 Ekim-2 Kasım 2000, Antalya, Kongre Kitab1, 2011, 23-26.

23. Batın, G, Akbulut, Y, Kanıta dayalı yaklaşım ve sağlık politikası, Ankara Sağllk Bilimleri Dergisi, 2012, 1(2), 115-132.

24. Hunter, DJ, Relationship Between Evidence and Policy: A Case of Evidence Based Policy or Policy Based Evidence? Public Health, 2009,123(9), 583-586.

25. Melnyk, BM, Fineout-Overholt, E, Giggleman, M, Cruz, R, Correlates among cognitive beliefs, EBP implementation, organizational culture, cohesion and job satisfaction in evidencebased practice mentors from a community hospital system, Nursing Outlook, 2010, 58, 301-308.

http://edergi.cbu.edu.tr/ojs/index.php/cbusbed isimli yazarın CBU-SBED başlıklı eseri bu Creative Commons Alıntı-Gayriticari4.0 Uluslararası Lisansı ile lisanslanmıştır.

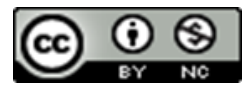

